Journal of Engineering and Applied Sciences 15 (1): 88-93, 2020

ISSN: 1816-949X

(C) Medwell Journals, 2020

\title{
Mathematical Model of the March of a Bipedal Robot Applying Quaternions Oriented to the Development of Anthropomorphic Robots
}

\author{
${ }^{1}$ Jorge Luis Aroca Trujillo, ${ }^{2}$ Leonardo Broche Vazquez and ${ }^{1}$ Ruthber Rodriguez Serrezuela \\ ${ }^{1}$ University Corporation of Huila, Neiva, Huila, Colombia \\ ${ }^{2}$ Universidad de Oriente, Santiago de Cuba, Cuba
}

\begin{abstract}
Humans have characteristic movements in the legsthatt end to be discontinuous with respect to the ground have the ability to evade obstacles, move on planes that have some degree of inclination and ascend/ descend stairs. Bipedal robots have a certain adaptation to a wide variety of surfaces where humans do the essential to live and work, a clear example can be seen when transported objects where we notice the recovery and movement in dangerous environments, among others. The main objective of this study is the development to make a mathematical model of the kinematics of a biped robot.
\end{abstract}

Key words: Biped, quaternions, kinematics, mechatronics, adaptation, inclination

\section{INTRODUCTION}

When performing the exercise of a continuous march on the legs we can see that it presents a discontinuity of contact with the ground, the action to avoid obstacles to move in inclined surfaces and to ascend/descend stairs. Walking on bipedal robots likewise, it tends to have some ability to move in broken and uneven environments where the human being works and lives because of that the human can perform supervision, maintenance and assistance tasks in all environments where humans. They may have the freedom to move with their lower extremities. Bipedal robots have mechatronic systems of potential use to be able to make an industrial use in relation to the transport of loads, making it easier to task, the transport of people in irregular terrain, the possibility of rescue of human beings in eventualities such as disasters. The possibility of operating in hazardous environments and other operations where humans may suffer from calamities. The bipedal contour taken by the robot is one of the main technologies indispensable for the design and development of an and roidor robot, the most human being possible or humanoid such as the one shown in Fig. 1. If we see the mathematical model for the kinematics of the movement of the biped robot of this research, this one has a configuration to realize the union of seven elements that have to be connected by a series of joints impinges on the rotation with approximately one degree of freedom each, forming of that anthropomorphic a hybrid structure of six Degrees of Freedom (DoF) enabled.

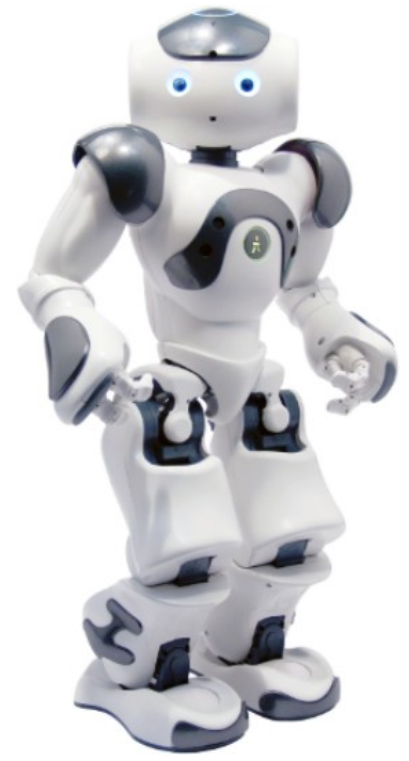

Fig. 1: Android or humanoid robot based on biped robot (Gouaillier et al., 2010)

\section{MATERIALS AND METHODS}

The TDMB EBS can transmit too many emergency alert biomechanics is the opening for the fulfillment of the use that is given to the application of the principles of mechanics to the human body, according to Smith (Chaudhary and Prasad, 2011). Cinematic can be defined as the set of biomechanical procedures in order to obtain the cinematic relevance needed to determine the position and motion of living beings accurately. The reare studies

Corresponding Author: Jorge Luis Aroca Trujillo, Mechatronics Engineering, University Corporation of Huila, Corhuila, Neiva, Huila, Colombia 


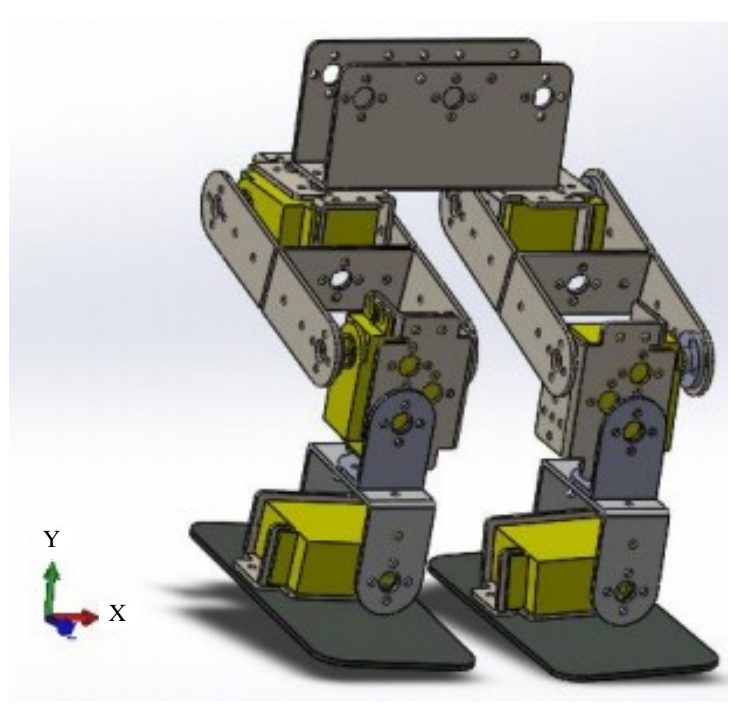

Fig. 2: Biped robot design in solidworks

to determine and accurately calculate the forces in the muscles when they are the external forces, presented by Braune and Fischer (Iqbal et al., 2012) who also did the study to calculate the trajectories, velocities, accelerations, forces and torques in the joints where they are denoted the segments of the human body in 31 phases of the gait cycle, thus, establishing with their studies the scientific basis for the analysis of the human gait. With the emergence of microelectronics began to use light-emitting diodes leds for the quantitative detection of trajectories in space, placed these led sat relevant points in the body of the individual and connected by wires to measure the quantities involved in the movement, according with Pedotti. A neat comparison between the different motion systems used in biomechanics can be found in Diaz Becerra (Iqbal et al., 2012).

Bipedal robots: In 1964, it was designed and implemented in Russia a biped mechanism capable of changing and transforming the rotation movement in translation based on the mechanism of Chebyshev (Fig. 2).

In 1968 proposed the implementation of a machine for an ideal floor that was a body supported by two legs without mass in 1973 the first studies on bipedal locomotion and control were realized and presented and the term Zero Moment Point ZMP was created. In 1969 in Japan the construction of one of the first bipedal robots in ananthropomorphic form was carried out at Waseda University called WAP-1 by Takanobu et al. (1993), Yamaguchi et al. (1993, 1994) Takanishi et al. (1985). In 1971 the biped robot WL-5 of 11 DoF was presented with control by computer. In 1973, WABOT-1 was created, a statically stable humanoid anthropomorphic robot adapted for the march, years later, Kato and his collaborators develop a type of quasi-dynamic locomotion whose main feature was that the transition from the support phase from one foot to the other foot occurred very fast and without performing the double support phase. In 1981, Kato and his collaborators developed the WL-9 DR which was a three-dimensional model of the lower limbsandin1985 the WL-10R with servomotors, structural components in carbon fiber, articulation in the pelvis that makes it possible to move side-ways, turn, march forward and march backward. In 1988, WL-12R appeared with 8 DoF for the legs and 2 DoF for the trunk with force sensors in the feet and in the joints with hydraulic actuators and with a step of $30 \mathrm{~cm}$ in $0.8 \mathrm{sec}$ (Mita et al., 1984). About 5 versions of the Chiba Walker CW biped robot were made at Tokyo University with seven segments, six CC engines and 5 DoF. Thus, in the industry of Japan have been developed experimental bipeds of 5, 7 and 9 DoF actuated with hydraulic servomotors that can walk in irregular environments. In Brazil, the researchers have published works of experimental and the oretical bipedal robots (Iqbal et al., 2012).

He experimented with a biped robot type RB-1 and developed the model of kinematics with matrices of homogeneous transformations for the orientation and analysis of the march by geometric methods (Behnke, 2006; Geng, 2014; Serrezuela et al., 2018; Carvajal et al., 2016).

The bipedal robot BR-1: The biped robot $\mathrm{RB}-1$ is an articulated mechanism with seven rigid segments representing the lower limbs of the human body joined together by means of rotating joints with a DoF each, capable of running on a flat surface in a statically stable. The angles of rotation in the joints are identified as $q_{i}$ where $\mathrm{i}=1,2, \ldots, 6$, the seven rigid segments of the biped robot are connected together by joints and in each of them coordinate systems are established. The seven rigid segments are the two feet, the two legs, the two thighs and the pelvis. This seven-element mechanism is a hybrid structure and for its model is considered as an open kinematic chain with instantaneous equilibrium when one of the two feet is in contact with the ground. In equilibrium the singular configurations are minimized. The head, trunk and the anthropomorphic robot's extremities are modeled as a rigid segment integrated into the pelvic segment. Traditionally, industrial robots are modeled with successive homogeneous transformation matrices, applied from the fixed coordinates of the base to the coordinates of the center point of the TCP claw. In this case the IR- 1 is modeled like these serial robots 
but instead of applying homogeneous transformations successive. From the base, quaternion are applied. For this analysis of kinematics, the instantaneous fixed point is considered to be where one of the feet is in contact with the ground and is called the inertial reference base while the other rotational joints are moving. When the rolling foot approaches the ground, the inertial reference base is instantly transferred to that foot and so on. This way we analyze the progress of this RB-1 to model the motion kinematics (Whitty, 2012; Gouaillier et al., 2009).

Once established the location of fixed and mobile bases, it is necessary to establish the relationships between them that is how to represent the same vector in each of the bases. It is considered that the transformation of any vector from base B1-B2 is performed by multiplying the vector by the transformation matrix MT1. Similarly, to transform a vector from Base B2-B1, simply Multiply it by the Inverse of MT1 because a property of the transformation matrix is that $\left[\mathrm{MT}_{\mathrm{i}}\right]^{-1}=\left[\mathrm{MT}_{\mathrm{i}}\right]^{\mathrm{T}}$ with quaternion the analysis happens in a similar way because they are also vector representations where it is true that $\mathrm{q}^{-1}=\mathrm{q}^{\mathrm{T}}$ that is the inverse of aquaternion is equal to its transposed.

\section{RESULTS AND DISCUSSION}

Quaternios: The quaternions are defined as the sum $\mathrm{q}=\mathrm{q}_{0}+\mathrm{q}$ with the following expanded representation $\mathrm{q}=$ $\mathrm{q}_{0}+\mathrm{iq}_{1}+\mathrm{jq}_{2}+\mathrm{kq}_{3}$. Its conjugate is similar to the conjugate of a complex number and is written $\mathrm{q}^{*}=\mathrm{q}_{0}-\mathrm{iq}_{1}-\mathrm{jq}_{2}-\mathrm{kq}_{3}$ which is equal to the inverse of the quaternion $\mathrm{q}^{(-1)}=\mathrm{q}^{*}$.

The product of quaternions is complicated and is defined as the fundamental special product that satisfies the following vector rules:

$$
\begin{aligned}
& i^{2}=j^{2}=k^{2}=-1 \\
& J_{i}=-k, k j=-i, i k=-j
\end{aligned}
$$

An angle can be related to a quaternion in a manner similar to how an angle can be associated with a rotation matrix (Dam et al., 1998). Based on this consideration, the quaternion that defines the operator is always a normalized quaternion or unit quaternion of the form; $\mathrm{Aq}^{2}$ $+|\mathrm{q}|^{2}=1$ alogousto $\cos ^{2} \theta+\sin ^{2} \theta=1$ in where $\theta$ it is defined and satisfies the constraint $\pi<\theta \leq \pi$. The product of quaternion when $\mathrm{p}=\cos (\alpha)+\mathrm{ksin}(\alpha)$ and $\mathrm{q}=\cos$ $(\beta)+k \sin (\beta)$ is defined as the product special of quaternions and is written:

$$
p q=p_{o} q_{o}-p_{o} q+q_{o} p+p_{x} q
$$

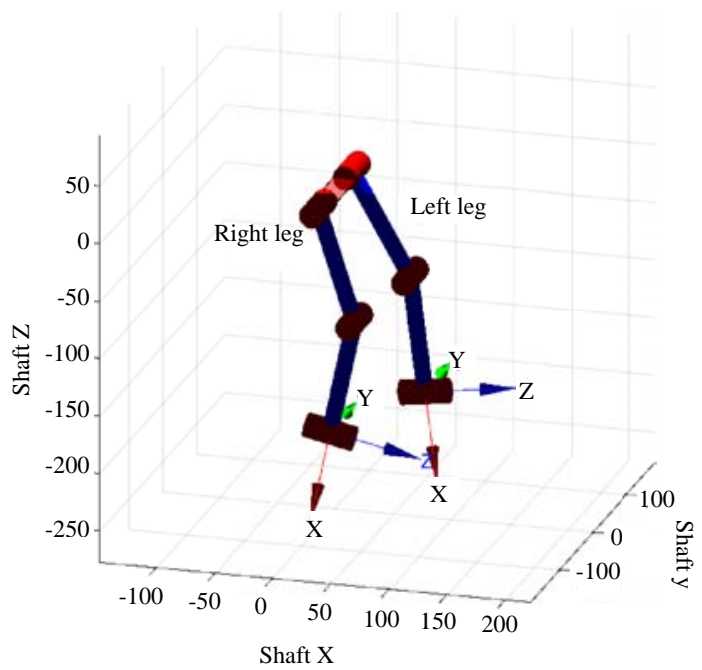

Fig. 3: RB1 coordinate system (Corke, 2017; Trujillo et al., 2017, 2018)

The triple quaternion product expressed $\mathrm{q}^{0} \mathrm{v}^{0} \mathrm{q}^{*}$ are interpreted as quaternion rotation operators. For get qaternion rotate operators from a vector in space $|\mathrm{R}|^{*}$ It is necessary that the vector in consideration. It is necessary that the vector in consideration is a pure quaternion that $\mathrm{v}$ is a pure quaternion that is $\mathrm{v}=$ $0+v$. To define a quaternion rotation operator represented by $\mathrm{L}_{\mathrm{q}}$ associated with the quaternion $\mathrm{q}$ and applied to a vector in space $v \in \mathrm{R}^{3}$ is developed as follows: to define a quaternion rotation operator represented by $\mathrm{R}^{3}$. The axis of rotation is the vector part of the quaternion $\mathrm{q}$ and the angle of rotation is twice the angle associated with the quaternion q. The first algebraic property of this operator is its linearity, that is and the second algebraic property is that its norm or length is invariant under the quaternion operator $\left|\mathrm{L}_{\mathrm{q}}(\mathrm{v})\right|=|\mathrm{v}|$. This property is necessary if the operator is to describe a rotation. The three terms of the expression can be represented in expanded form with matrices shape $\mathrm{W}=\mathrm{q}(\mathrm{v}) \mathrm{q}^{*}=\mathrm{Qv}$. Where Q is the matrix (Sabatini, 2005; Serrezuela et al., 2017).

Based on the above considerations we have the following theorem: for any unitary quaternion of the form $\mathrm{q}=\mathrm{q}_{\mathrm{o}}+\mathrm{q}=\cos \theta+\sin \theta$ and for any vector $\mathrm{v} \in \mathrm{R}^{3}$ la action of the operator $\mathrm{LqV}=\mathrm{qVq}^{*}$ on $\mathrm{v}$ can be interpreted geometrically as a rotation 2 of vector $\mathrm{v}$ about $\mathrm{q}$ as the axis of rotation (Kuipers, 1998; Trujillo et al., 2017, 2018).

Kinematics with quaternion: Figure 3 represents the coordinate system for RB-1 from which the mathematical model of direct kinematics with quaternions is obtained: 
- $\quad$ Null displacement and rotation $\theta_{0}$ around $\mathrm{Z}_{0}: \mathrm{P}_{1}$ (Null) and $\mathrm{R}_{1}\left(\mathrm{Z}_{0}, \theta_{0}\right)$

- Displacement of $\mathrm{O}_{0}$ a distance $\mathrm{d}_{1}$ along $\mathrm{Y}_{0}$ and rotation $\theta_{1}$ around $Z_{1}$ arriving at the system $\mathrm{O}_{1}: \mathrm{P}_{2}\left(\mathrm{Y}_{0}\right.$, $\left.\mathrm{d}_{1}\right)$ and $\mathrm{R}_{2}\left(\mathrm{Z}_{1}, \theta_{1}\right)$

- Displacement of $\mathrm{O}_{1}$ a distance $\mathrm{d}_{2}$ along $\mathrm{Y} 1$ and rotation $\theta_{2}$ around $Z_{2}$ arriving at the system $\mathrm{O}_{2}: \mathrm{P}_{3}\left(\mathrm{Y}_{1}\right.$, $\left.\mathrm{d}_{2}\right)$ and $\mathrm{R}_{3}\left(\mathrm{Z}_{2}, \theta_{2}\right)$

- Displacement of $\mathrm{O}_{2}$ a distance $\mathrm{d}_{3}$ along $-\mathrm{Z}_{2}$ and rotation $\theta_{3}$ around $Z_{3}$ arriving at the system $\mathrm{O}_{3}: \mathrm{P}_{4}\left(-\mathrm{Z}_{2}, \mathrm{~d}_{3}\right)$ and $\mathrm{R}_{4}\left(\mathrm{Z}_{3}, \theta_{3}\right)$

- Displacement of $\mathrm{O}_{3}$ a distance $\mathrm{d}_{4}$ along $-\mathrm{Y}_{3}$ and rotation $\theta_{4}$ around $Z_{4}$ arriving at the system $\mathrm{O}_{4}: \mathrm{P}_{5}\left(-\mathrm{Y}_{3}, \mathrm{~d}_{4}\right)$ and $\mathrm{R}_{5}\left(\mathrm{Z}_{4}, \theta_{4}\right)$

- Displacement of $\mathrm{O}_{4}$ a distance $d_{5}$ along $-Y_{4}$ and rotation $\theta_{5}$ around $Z_{5}$ arriving at the system $\mathrm{O}_{5}: \mathrm{P}_{6}\left(-\mathrm{Y}_{4}, \mathrm{~d}_{5}\right)$ and $\mathrm{R}_{6}\left(\mathrm{Z}_{5}, \theta_{5}\right)$

where the displacements $\mathrm{P}$ are defined by the following position vectors:

$$
\begin{array}{lll}
\mathrm{r}_{1}=0,0,0 & \mathrm{r}_{2}=0, \mathrm{~d}_{1}, 0 & \mathrm{r}_{3}=0, \mathrm{~d}_{2}, 0 \\
\mathrm{r}_{4}=0,0, \mathrm{~d}_{3} & \mathrm{r}_{5}=0,-\mathrm{d}_{4}, 0 & \mathrm{r}_{6}=0,-\mathrm{d}_{5}, 0
\end{array}
$$

Rotations are defined by the following quaternions for:

$$
\begin{aligned}
& \hat{\mathrm{C}}=\operatorname{COS} \frac{\theta_{\mathrm{i}}}{2} \quad \text { and } \hat{\mathrm{S}}=\sin \frac{\theta_{\mathrm{i}}}{2} \\
& \mathrm{Q}_{\mathrm{i}}=(\hat{\mathrm{C}}, 0,0, \hat{\mathrm{S}}) \quad \text { for } \quad \mathrm{i}=1-6
\end{aligned}
$$

If a translation is first applied represented by the vector $\mathrm{r}$ followed by a rotation represented by the quaternion $Q$ to the system $\mathrm{O}_{\mathrm{i}} \mathrm{X}_{\mathrm{i}} \mathrm{Y}_{\mathrm{i}} \mathrm{Z}_{\mathrm{i}}$ results in a new system $\mathrm{O}_{(\mathrm{i}+1)} \mathrm{X}_{(\mathrm{i}+1)} \mathrm{Y}_{(\mathrm{i}+1)} \mathrm{Z}_{(\mathrm{i}+1)}$ such that the coordinates of a position vector $\mathrm{p}$ in the system $\mathrm{O}_{\mathrm{i}} \mathrm{X}_{\mathrm{i}} \mathrm{Y}_{\mathrm{i}} \mathrm{Z}_{\mathrm{i}}$ known in the system $\mathrm{O}_{(i+1)} \mathrm{X}_{(i+1)} \mathrm{Y}_{(i+1)} \mathrm{Z}_{(\mathrm{i}+1)}$ can be calculated with the following expression math:

$$
\mathrm{P}=\left(0, \mathrm{P}_{\mathrm{i}-1}\right)=\mathrm{Q}_{1}^{\circ}\left(0, \mathrm{P}_{\mathrm{i}}\right)^{\circ} \mathrm{Q}_{\mathrm{i}}^{+}+\left(0, \mathrm{r}_{\mathrm{i}}\right)
$$

And for the rotation can be expressed by the following Eq. 7:

$$
\mathrm{R}=\mathrm{R}_{\mathrm{i}-1}=\mathrm{Q}_{\mathrm{i}} \mathrm{R}_{\mathrm{i}}
$$

Definition of position and orientation: Where $r_{i}$ and $Q_{i}$ are respectively, displacement and subsequent rotation which allow converting $\mathrm{Q}$ (i-1) to $\mathrm{Q}_{\mathrm{i}}$. Applying consecutively the expressions 6 and 7 from the system $\mathrm{O}_{\mathrm{o}}$ to the system $\mathrm{O}_{5}$ gives the following set of expressions for $\mathrm{i}=1-6$ :

$$
\begin{aligned}
& \left(0, P_{0}\right)=Q_{1}^{\circ}\left(0, P_{1}\right)^{\circ} Q_{1}^{*}+\left(0, r_{1}\right) \\
& R_{0}=Q_{1} R_{1} \\
& \left(0, P_{1}\right)=Q_{2}\left(0, P_{2}\right) Q_{2}+\left(0, r_{2}\right) \\
& R_{1}=Q_{2} R_{2} \\
& \left(0, P_{2}\right)=Q^{\circ}\left(0, P_{3}\right)^{\circ} Q^{*}+\left(0, r_{3}\right) \\
& R_{2}=Q_{3} R_{3} \\
& \left(0, P_{3}\right)=Q_{4}^{\circ}\left(0, P_{4}\right)^{\circ} Q_{4}^{*}+\left(0, r_{4}\right) \\
& R_{3}=Q_{4} R_{4} \\
& \left(0, P_{4}\right)=Q_{5}^{\circ}\left(0, P_{5}\right)^{\circ} Q_{5}^{*}+\left(0, r_{5}\right) \\
& R_{4}=Q_{5} R_{5} \\
& \left(0, P_{5}\right)=Q_{6}^{\circ}\left(0, P_{6}\right)^{\circ} Q_{6}^{*}+\left(0, r_{6}\right) \\
& R_{5}=Q_{6} R_{6}
\end{aligned}
$$

Position calculation: By consecutive substitution in the previous Eq. 6, we obtain (Fig. 4):

$$
\begin{aligned}
\left(0, \mathrm{P}_{0}\right)= & \mathrm{Q}_{1} \mathrm{Q}_{2} \mathrm{Q}_{3} \mathrm{Q}_{4} \mathrm{Q}_{5} \mathrm{Q}_{6}\left(0, \mathrm{r}_{7}\right) \mathrm{Q}_{6}{ }_{6} \mathrm{Q}_{5}^{*} \mathrm{Q}_{4}^{*} \\
& \mathrm{Q}_{3}^{*} \mathrm{Q}_{2}^{*} \mathrm{Q}_{1}^{*} \\
& +\mathrm{Q}_{1} \mathrm{Q}_{2} \mathrm{Q}_{3} \mathrm{Q}_{4} \mathrm{Q}_{5}\left(0, \mathrm{r}_{6}\right) \mathrm{Q}_{5}^{*} \mathrm{Q}^{*}{ }_{4} \\
& \mathrm{Q}_{3}^{*} \mathrm{Q}_{2}^{*} \mathrm{Q}_{1}^{*} \\
& +\mathrm{Q}_{1} \mathrm{Q}_{2} \mathrm{Q}_{3} \mathrm{Q}_{4}\left(0, \mathrm{r}_{5}\right) \mathrm{Q}_{4}^{*} \mathrm{Q}_{3}^{*} \\
& \mathrm{Q}_{2}^{*} \mathrm{Q}_{1}^{*} \\
+ & \mathrm{Q}_{1} \mathrm{Q}_{2} \mathrm{Q}_{3}\left(0, \mathrm{r}_{4}\right) \mathrm{Q}_{3}^{*} \mathrm{Q}_{2}^{*} \mathrm{Q}_{1}^{*}+ \\
& \mathrm{Q}_{1} \mathrm{Q}_{2}\left(0, \mathrm{r}_{3}\right) \mathrm{Q}_{2}^{*} \mathrm{Q}_{1}^{*} \\
+ & \mathrm{Q}_{1}\left(0, \mathrm{r}_{2}\right) \mathrm{Q}^{*}{ }_{1}+\left(0, \mathrm{r}_{1}\right) \\
\left(0, \mathrm{P}_{0}\right)= & \mathrm{Q}_{123456}\left(0, \mathrm{r}_{7}\right) \mathrm{Q}_{654321}^{*} \\
+ & \mathrm{Q}_{12345}\left(0, \mathrm{r}_{6}\right) \mathrm{Q}_{54321}^{*}+\mathrm{Q}_{1234}\left(0, \mathrm{r}_{5}\right) \mathrm{Q}^{*}{ }_{4321} \\
& +\mathrm{Q}_{123}\left(0, \mathrm{r}_{4}\right) \mathrm{Q}_{321}^{*}+\mathrm{Q}_{12}(0,3) \mathrm{Q}_{21}^{*} \\
+ & \mathrm{Q}_{1}(0,2) \mathrm{Q}_{1}^{*}+\left(0, \mathrm{r}_{1}\right)
\end{aligned}
$$

Considering that:

$$
\mathrm{Q}_{1}=\mathrm{Q}_{2}=\mathrm{Q}_{3}=\mathrm{Q}_{4}=\mathrm{Q}_{5}=\mathrm{Q}_{6}=(\hat{\mathrm{C}} \theta, 0,0, \hat{\mathrm{S}} \theta)
$$

For the articulation variables. Generalizing you can write:

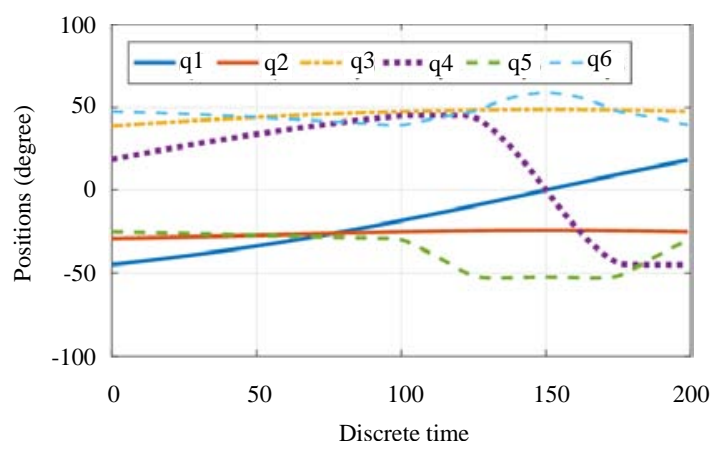

Fig. 4: Joint movements 


$$
\left[\mathrm{P}_{\mathrm{o}}\right]=[\mathrm{Q}]_{\mathrm{i}=1}^{\mathrm{m}}\left[\mathrm{P}_{\mathrm{m}}\right] \cdot\left[\mathrm{Q}^{*}\right]_{\mathrm{m}}^{\mathrm{i}=1}+\sum_{1}^{\mathrm{m}}\left(\mathrm{Q}_{1}^{\mathrm{m} \cdot \mathrm{i}}\right) \cdot \mathrm{r}_{\mathrm{m}}^{\mathrm{i}} \cdot \mathrm{Q}_{\mathrm{m}-1}^{\mathrm{i}}
$$

Writing in summary form:

$$
\mathrm{P}_{\mathrm{o}}=\mathrm{W}+\sum_{1}^{\mathrm{m}} \mathrm{W}_{\mathrm{i}}
$$

Where:

$\left[\mathrm{P}_{0}\right]$ : Quaternion of position of the frame of the robot claw relative to the frame of the fixed base

$\left[\mathrm{Q}_{\mathrm{i}=1}^{\mathrm{m}} \quad\right.$ : Product of quaternions of rotation $\mathrm{Q}$ from $\mathrm{i}=\mathrm{m}$ $1,2, \ldots, 10$ to $\mathrm{m}=10$

$\left[\mathrm{P}_{\mathrm{m}}\right]$ : Quaternion of position of the target system with respect to the coordinate system $\mathrm{m}$. If the system target matches the claw system $\mathrm{m}$, then we have $\mathrm{P}=0,0,0,0$

$\left[\mathrm{Q}^{-}\right]_{\mathrm{m}}^{\mathrm{i}=1}$ : Product of conjugated quaternions from $\mathrm{m}=\mathrm{i}=$ $10,9, \ldots$, i, when $\mathrm{i}=1$

$\sum_{i}^{m} w$ : Summation product of the quaternion operator for:

$$
\mathrm{W}=[\mathrm{Q}]_{\mathrm{i}=1}^{\mathrm{m}}\left[\mathrm{P}_{\mathrm{m}}\right] \cdot\left[\mathrm{Q}^{-}\right]_{\mathrm{m}}^{\mathrm{i}=1}
$$

And:

$$
\sum_{1}^{\mathrm{m}}\left(\mathrm{Q}_{1}^{\mathrm{m} \cdot \mathrm{i}}\right) \cdot \mathrm{r}_{\mathrm{m}}^{\mathrm{i}} \cdot \mathrm{Q}_{\mathrm{m}-1}^{\mathrm{i}}
$$

Rotation calculation: The relationships between the quaternion that define the rotation of the joints in the coordinate system $\mathrm{B} 2$, that is, $\mathrm{O}_{5}$ with respect to a coordinate system of $\mathrm{B} 1$ that is $\mathrm{O}_{0}$ by composition quaternions applying the Eq. (3); If $i=1,2, \ldots, \mathrm{m}$ and $\mathrm{m}=6$, we have:

$$
\begin{aligned}
& \mathrm{R}_{\mathrm{i}-1}=\mathrm{Q}_{1} \mathrm{R}_{\mathrm{i}} \\
& \mathrm{R}_{\mathrm{o}}=\mathrm{Q}_{1} \mathrm{Q}_{2} \mathrm{Q}_{3} \mathrm{Q}_{4} \mathrm{Q}_{5} \mathrm{Q}_{6} \mathrm{R}_{6}=\mathrm{Q}_{123456} \mathrm{R}_{6}
\end{aligned}
$$

Generalizing you can write:

$$
\mathrm{R}_{\mathrm{o}}=\mathrm{Q}_{\mathrm{i}}^{\mathrm{m}} \mathrm{R}_{\mathrm{m}}
$$

With Eq. 13 and 14 the position and orientation of base B2 of RB-1 can be determined with respect to base coordinate system B1 as a function of articulation, coordinates $\theta_{1}, \theta_{2}, \theta_{3}, \theta_{4}, \theta_{5}$ and $\theta_{6}$, corresponding, therefore to the solution of the problem of direct kinematics.

\section{CONCLUSION}

Quaternion are determined as an essential and traditional mathematical tool that is used to calculate the mathematical model of the kinematics of robotic systems, manipulators, bipedal robots and anthropomorphic robots. The quaternions in can be compared to homogeneous transformation matrices can be faster for the calculation when it is necessary to know only one characteristic, like the position or the orientation.

To perform the computation of bipedal kinematics is understood to be fundamental for the development of human oidrobots or anthropomorphic and mathematical model of kinematics is also the basis for the programming and autonomous control of these mechatronic devices.

\section{REFERENCES}

Behnke, S., 2006. Online trajectory generation for omnidirectional biped walking. Proceedings of the IEEE International Conference on Robotics and Automation, May 15-19, 2006, Orlando, FL., USA., pp: 1597-1603.

Carvajal, R.J.H., R.R. Serrezuela, J.A.Q. Lopez and K.L.R. Perdomo, 2016. LQR hybrid approach control of a robotic arm two degrees of freedom. Intl. J. Appl. Eng. Res., 11: 9221-9228.

Chaudhary, H. and R. Prasad, 2011. Intelligent inverse kinematic control of scorbot-er $\mathrm{v}$ plus robot manipulator. Intl. J. Adv. Eng. Technol., 1: 158-169.

Corke, P., 2017. Robotics, Vision and Control: Fundamental Algorithms in MATLAB ${ }^{\circledR}$ Second, Completely Revised. Vol. 118/2nd Edn., Springer, Berlin, Germany, ISBN:9783319544137, Pages: 693.

Dam, E.B., M. Koch and M. Lillholm, 1998. Quaternions, Interpolation and Animation. Datalogisk Institut, Kobenhavns Universitet (DIKU), Copenhagen, Denmark, Pages: 98.

Geng, T., 2014. Torso inclination enables faster walking in a planar biped robot with passive ankles. IEEE. Trans. Rob., 30: 753-758.

Gouaillier, D., C. Collette and C. Kilner, 2010. Omni-directional closed-loop walk for NAO. Proceedings of the 2010 10th IEEE-RAS International Conference on Humanoid Robots, December 6-8, 2010, IEEE, Nashville, Tennessee, USA., pp: 448-454.

Gouaillier, D., V. Hugel, P. Blazevic, C. Kilner, J. Monceaux, P. Lafourcade and B. Maisonnier, 2009. Mechatronic design of NAO humanoid. Proceedings of the 2009 IEEE International Conference on Robotics and Automation, May 12-17, 2009, IEEE, Kobe, Japan, pp: 769-774.

Iqbal, J., R.U. Islam and H. Khan, 2012. Modeling and analysis of a 6 DOF robotic arm manipulator. Can. J. Electr. Electronics Eng., 3: 300-306. 
Kuipers, J.B., 1998. Quaternions and Rotation Sequences: A Primer with Applications to Orbits, Aerospace and Virtual Reality. Princeton University Press, Princeton, New Jersey, USA.,.

Mita, T., T. Yamaguchi, T. Kashiwase and T. Kawase, 1984. Realization of a high speed biped using modern control theory. Intl. J. Control, 40: 107-119.

Sabatini, A.M., 2005. Quaternion-based strap-down integration method for applications of inertial sensing to gait analysis. Med. Biol. Eng. Comput., 43: 94-101.

Serrezuela, R.R., A.F.C. Chavarro, M.A.T. Cardozo, A.L. Toquica and L.F.O. Martinez, 2017. Kinematic modelling of a robotic arm manipulator using matlab. J. Eng. Appl. Sci., 12: 2037-2045.

Serrezuela, R.R., J.A. Trujillo, A.N. Ramos and J.R. Zarta, 2018. Applications Alternatives of Multivariable Control in the Tower Distillation and Evaporation Plant. In: Advanced Engineering Research and Applications, Ajaykumar, B.S. and D. Sarkar (Eds.). Research India Publication, Delhi, India, pp: 452-465.

Takanishi, A., M. Ishida, Y. Yamazaki and I. Kato, 1985. The realization of dynamic walking by the biped walking robot WL-10 RD. J. Rob. Soc. Japan, 3: 325-336.
Takanobu, H., A. Takanishi and I. Kato, 1993. Design of a mastication robot mechanism using a human skull model. Proceedings of 1993 IEEE/RSJ International Conference on Intelligent Robots and Systems (IROS'93) Vol. 1, July 26-30, 1993, IEEE, Yokohama, Japan, pp: 203-208.

Trujillo, J.L.A., A. Perez-Ruiz and R. Rodriguez Serrezuela, 2017. Generation and control of basic geometric trajectories for a robot manipulator using compact RIO®. J. Rob., 2017: 1-11.

Trujillo, J.L.A., R.R. Serrezuela, V. Azhmyakov and R.S. Zamora, 2018. Kinematic model of the scorbot 4PC manipulator implemented in Matlabs Guide. Contemp. Eng. Sci., 11: 183-199.

Whitty, M., 2012. Robotics, vision and control: Fundamental algorithms in MATLAB. Ind. Rob. Intl. J., Vol. 39,

Yamaguchi, J.I., A. Takanishi and I. Kato, 1993. Development of a biped walking robot compensating for three-axis moment by trunk motion. J. Rob. Soc. Japan, 11: 581-586.

Yamaguchi, J.I., A. Takanishi and I. Kato, 1994. Development of a biped walking robot adapting to a horizontally uneven surface. Proceedings of IEEE/RSJ International Conference on Intelligent Robots and Systems (IROS'94) Vol. 2, September 12-16, 1994, IEEE, Munich, Germany, pp: 1156-1163. 